\title{
The Speed Test For Agility Reactive Sprint Mirror Drill Training
}

\author{
Ramadhany Hananto Puriana ${ }^{1)}$, Riga Mardhika ${ }^{2)}$ \\ Program studi Pendidikan Jasmani, Fakultas Pedagogy dan Psikology \\ 1,2Universitas PGRI Adi Buana Surabaya, Jawa Timur Indonesia \\ Email: ${ }^{1}$ ramadhany@unipasby.ac.id, ${ }^{2}$ rigamardhika@ unipasby.ac.id
}

\begin{abstract}
This study to analyze the impact of the reactive agility sprint mirror drill exercise in the increasing the speed. . This research was done at UNIPA Surabaya by using a sample of soccer athletes in Unipa Surabaya by using the original pairing technique in determining the sample group. This type of quantitative research is the type of research that is suitable for testing the speed of reactive agility sprint mirror drill training by applying the quasi experimental design method. To measure the speed was taken by using the $30 \mathrm{~m}$ sprint test. The results of this study indicate that the Reactive Agility Sprint Mirror Drill training has a significant effect on speed, as indicated by the results of the normality test using the Kolmogorov Smirnov test pre and post velocity $p=0.723(p>0.05)$ and $p=0.166(p>0.05)$. ) and the homogeneity test used the Leavenes Test with the results of pre $p=0.131$ ( $p>0.05)$ and post $p 0.146(p>0.05)$, while to determine the results of the T-test used paired sample test with dependent variables in the experimental group with numbers significance $p=0.003(p<0.05)$, in other words it has an increase in effect, meaning that there is a significant effect, while the T-test results of the dependent variable in the control group obtained a significance number of $p=0.000(p<0.05)$, the conclusion is increase effect.
\end{abstract}

Keywords: Soccer, Speed, Reactive Agility Sprint Mirror Drill.

\section{Uji Kecepatan Terhadap Pelatihan Reactive Agility Sprint Mirror Drill ABSTRAK}

Penelitian ini bertujuan untuk menganalisis besarnya dampak yang dihasilkan latihan reactive agility sprint mirror drill terhadap peningkatan kecepatan (speed). Penelitian ini dilaksanakan di UNIPA Surabaya dengan mamakai sampel atlet UKM sepak bola Unipa Surabaya dengan menggunakan teknik oridinal pairing didalam menentukan kelompok sampel. Jenis penelitian Kuantitatif adalah jenis penelitian yang sesuai untuk menguji kecepatan terhadap pelatihan reactive agility sprint mirror drill dengan menerapkan metode quasi experimental design. Untuk mengukur kecepatan mengunakan sprint test $30 \mathrm{~m}$. Hasil penelitian ini menunjukkan bahwa pelatihan Reactive Agility Sprint Mirror Drill berpengaruh signifikan terhadap kecepatan, ditunjukkan dari hasil uji normalitas menggunakan kolmogorov smirnov test pre dan post kecepatan adalah $\mathrm{p}=0,723(\mathrm{p}>0,05)$ dan $\mathrm{p}=0,166(\mathrm{p}>0,05)$ dan uji homogenitas menggunakan leavenes Test dengan hasil pre $p=0,131(\mathrm{p}>0,05)$ dan post $\mathrm{p} 0.146(\mathrm{p}>0,05)$ sedangkan untuk mengetahui hasil uji- $\mathrm{T}$ menggunakan paired sampel test dengan variabel dependent pada kelompok eksperimen dengan angka signifikasi $\mathrm{p}=0,003(\mathrm{p}<0,05)$, dengan kata lain memiliki dampak kenaikan artinya terdapat pengaruh signifikan, sedangkan hasil uji $\mathrm{T}$ dari variabel dependent pada kelompok kontrol diperoleh angka signifikasi $\mathrm{p}=0,000$ $(\mathrm{p}<0,05)$, kesimpulannya ada efek kenaikan.

Kata Kunci: Sepak bola, Kecepatan, Reactive Agility Sprint Mirror Drill.

Info Artikel

P-ISSN 2613-9421

Dikirim

: 13 Mei 2020

Diterima : 30 Juli 2020

Dipublikasikan : 12 November 2020

$\bowtie$ Alamat korespondensi: ramadhany@unipasby.ac.id

Universitas PGRI Adi Buana Surabaya, Jl. Ngagel Dadi III No.3B/37, Ngagelrejo, Kec. Wonokromo, Kota SBY, Jawa

Timur 60234, Indonesia 


\section{PENDAHULUAN}

Dalam suatu permainan sepakbola kecepatan menjadi performa penting yang dibutuhkan setiap pemain, karena gerak cepat sebagai penunjang keahlian gerakan kesinambungan dalam kurun waktu yang sesingkat- singkatnya (Haugen et al., 2014). Salah satu contoh pada permainan sepakbola ketika operan bola dari teman satu ke teman lainnya dalam satu tim, pemain tersebut dengan sigap langsung menerima bola. Pergerakan seorang pemain tidak mudah diduga, karena tergantung situasi permainan. Gerakan seorang atlet tergantung arah datangnya bola, menghindari tekel lawan, melakukan sprint melewati lawan. Atlet sepakbola dituntut memiliki kecepatan (speed) yang baik. Dengan demikian permainan sepakbola adalah suatu permainan yang salah satunya mengutamakan kecepatan gerak (speed), oleh karena itu atlet harus dilatih untuk semakin mengembangkan kecepatan (Turner \& Stewart, 2014).

Kondisi fisik adalah kemampuan atlet untuk mempertahankan kerja fisik dengan keahlian bertahap. Dengan metode kualitatif dan kuantitatif kondisi fisik tersebut bisa dinilai. Keadaan fisik meliputi dua bidang, yaitu bidang kesegaran jasmani (physical fitness) dan bidang kesegaran gerak (motor fitness) (Satriya, 2011). Di dalam kondisi fisik, kecepatan (speed) yang baik sangat diperlukan dalam permainan sepakbola. Saat kecepatan atlet pesepakbola baik, oleh karena itu bisa mengontrol jalannya permainan dengan baik. Kecepatan (Speed) yang baik pada seorang atlet sepakbola agar mempermudah pemain untuk bergerak dengan cepat untuk melewati lawan dan berpindah posisi dengan cepat. Namun, kecepatan yang baik harus didukung beberapa keterampilan fisik salah satunya adalah kekuatan (strength) dan kelentukan (flexibility). Kecepatan (speed) adalah gabungan dari kekuatan, dan waktu reaksi. Jadi dapat disimpulkan bahwa kecepatan (speed) merupakan kombinasi dari beberapa komponen, salah satunya adalah kekuatan (strength)).

Dalam permainan sepakbola nilai kecepatan gerak sangat dominan, karena atlet sepakbola selalu sigap untuk diperlukan pada saat melakukan kecepatan reaksi kecepatan aksi, karena semua pemain sepakbola wajib memiliki kecepatan, karena pada saat permainan berlangsung pemain dituntut untuk secara cepat menggiring bola kearah gawang lawan. Penglihatan pemain sepakbola bisa 
Ramadhany Hananto Puriana ${ }^{1)}$, Riga Mardhika ${ }^{2)}$. Jp.jok (Jurnal Pendidikan. Jasmani, Olahraga dan Kesehatan). 4(1)

melakukan gerakan dengan cepat karena optiknya mendapatkan rangsangan, Contohnya waktu pemain sepakbola melindungi bola dengan sendirinya pemain tersebut memantau pergerakan lawan yang bertujuan merebut bola.

Reactive agility training (RAT) adalah motode pelatihan yang bertujuan menambah gerakan secepat mungkin (W. Kusnanik et al., 2019). Daya kerja otot/ kumpulan beberapa otot untuk menyalurkan rangsangan gerak dalam waktu yang cepat adalah gerak cepat (Sukadiyanto \& Muluk, 2011).

Menurut beberapa pakar terkait gerak cepat, dapat disimpulkan maka kecepatan merupakan keterampilan untuk memulai gerakan atau rangkaian gerakan secara berulang- ulang dengan kecepatan tinggi sebagai respons kepada rangsangan. Reactive agility training (RAT) tergolong pelatihan mengantisipasi serta pemungutan kepastian saat merespon gerakan (Young \& Rogers, 2014) Reactive agility merupakan latihan mengantisipasi dan pengambilan keputusan dengan perubahan kecepatan atau arah dalam menanggapi rangsangan (Henry et al., 2012). Penelitian ini penting dilakukan karena seperti yang kita ketahui bersama bahwasanya selama ini pelatihan reactive agility sprint mirror drill adalah latihan yang ditujukan untuk meningkatkan kelincahan, akan tetapi dalam penelitian ini akan dilakukan uji coba apakah pelatihan reactive agility sprint mirror drill juga bisa meningkatkan kecepatan.

\section{METODE}

Model penelitian yang dipakai yaitu riset kuantitatif dengan memakai model eksperimen semu (quasi experimental design). Konsep dari riset tersebut memakai matching-only design. Konsep riset kali ini tidak memakai random untuk memasukkan sampel penelitian ke dalam kelompok, akan tetapi memakai matching. Matching-only pretest-postest only control group design adalah penelitian yang menggunakan sistem matching terhadap subjek pada kelompok kontrol dan kelompok perlakuan. Jadi dalam penelitian ini kedua kelompok diberi tes awal (pretes) dengan tes yang sama, kemudian kelompok perlakuan diberikan latihan reactive agility sprint mirror drill sedangkan kelas kontrol diberi latihan konvensional. Kedua kelompok selanjutnya di tes dengan tes yang sama sebagai 
tes akhir (posttest), hasil keduanya dibandingkan dan diuji perbedaannya, demikian pula antara tes awal dengan tes akhir pada masing - masing kelompok dilakukan hal yang sama.

\section{Populasi}

Populasi merupakan wilayah generalisasi objek atau subjek yang mempunyai kualitas dan karakteristik tertentu yang ditetapkan oleh peneliti untuk dipelajari dan kemudian ditarik kesimpulan (Sugiyono, 2013). Populasinya yaitu semua mahasiswa laki- laki yang mengikuti UKM Futsal di Universitas PGRI Adi Buana Surabaya (UNIPA) berjumlah 175 mahasiswa. Pada riset kali ini peneliti hanya memerlukan $20 \%$ dari total populasi 175 mahasiswa yaitu 24 mahasiswa yang dijadikan sampel penelitian. Teknik pengelompokan sampel yang dipilih peneliti yaitu teknik simple random sampling.

\section{Sumber Data}

Data yang dipakai berasal dari data primer. Data primer adalah data yang diperoleh secara langsung ke objek penelitian, biasanya berasal dari kuesioner, wawancara atau pengamatan terhadap objek tertentu. Data primer pada penelitian ini yaitu hasil tes kecepatan dari seluruh mahasiswa putra jurusan PKO FKIP Universitas PGRI Adi Buana Surabaya (UNIPA) angkatan 2014, berjumlah 24 mahasiswa.

Dalam penelitian ini, peneliti menggunakan 24 mahasiswa putra sebagai sumber data. Peneliti akan membagi menjadi dua kelompok yaitu kelompok 1 dan 2 setelah mengetahui hasil tes awal berupa tes sprint $30 \mathrm{~m}$ untuk mengukur kecepatan. Hasil tes awal berupa tes kecepatan untuk menentukan dua kelompok itu akan digunakan ordinal pairing.

\section{Tempat, Alat, Waktu Pengambilan Data, dan Teknik Pengumpulan Data}

Penelitian dilaksanakan kurang lebih 12 minggu, 3 kali latihan tiap minggu dan jumlah total latihan adalah 36 kali. Peralatan yang digunakan yaitu: kun atau corong, meteran, stopwatch, alat tulis, lintasan Reactive Agility Sprint Mirror Drill. Dalam teknik pengumpulan data penelitian ini meliputi beberapa prosedur. Adapun prosedur tersebut adalah data yang diperlukan dalam penelitian pre - post adalah data kecepatan subyek penelitian sebelum mendapatkan pelatihan. Tes yang dilakukan untuk mengukur tingkat kecepatan yaitu tes Sprint 30m. Tes ini 
akan dilakukan 2 kali dan diambil hasil terbaiknya. Tujuan tes ini adalah untuk mengetahui kecepatan yang dimiliki seluruh sampel sebagai sumber data pada awal tes.

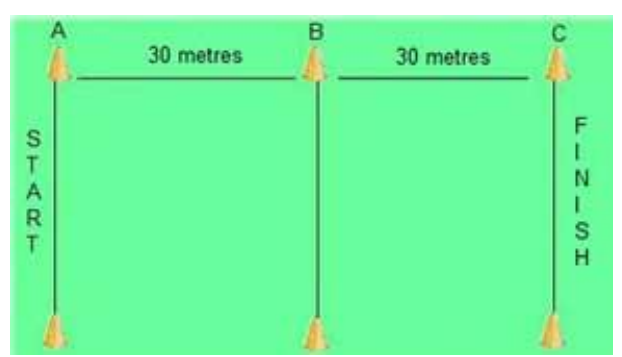

Gambar 1. Reactive Agility Sprint Mirror Drill

Sumber : (Effendi \& Rhamadhansyah, 2017)

Berikut tata cara pelaksanaan tes awal dan tes akhir:

(1) Sampel bersiap berdiri di garis start

(2) Menggunakan aba-aba " siap" sampel bersiap di garis start

(3) Sesudah aba-aba “yak" sampel berlari secepat-cepatnya melaju ke arah depan lurus dengan jarak tempuh 30 meter sampai garis finish

(4) Test dilakukan 2 kali, setelah berselang satu kali pelari

(5) Sampel dinyatakan gagal apabila menyebrang lintasan lainnya

(Dr. Widiyastuti, 2015)

\section{Program Latihan}

Sebelum program latihan tersebut disusun maka terlebih dahulu ditentukan denyut nadi maksimal atlet putra dari masing - masing latihan. Denyut nadi tersebut digunakan untuk menentukan beban latihan atau dosis latihan yang akan diberikan. Denyut Nadi berfungsi mengukur intensitas dengan menggunakan rumus: Denyut Nadi Maksimal $(\mathrm{DNM})=220$ - Usia (dalam tahun) (Ruslan, 2011). Contoh : seorang atlet putra yang berumur 21 tahun, DNM - nya $=220-$ 21 = 199 denyut nadi/menit.

Sedangkan intesitas untuk olahraga prestasi persentasenya adalah $80 \%-90 \%$ dari DNM (Widiyanto, 2014), 80/100 x 199 = 159,2 (batas maksimal). Cara menentukan intesitas dengan DNM. Atlet disuruh melakukan latihan gerakan reactive agility sprint drill sampai batas kelelahan maksimal, dengan syarat gerak yang benar tanpa recovery. 
Pelaksanaan latihan reactive agility sprint drill sebaiknya dilakukan 3 kali dalam seminggu selama delapan minggu karena reactive agility sprint drill, maka dari itu peneliti menggunakan acuan untuk peningkatan beban latihan setiap 2 minggu dengan pedoman buku bompa Periodization: Theory and Methodology Of Training (Tudor O. Bompa \& Buzzichelli, 2018).

\section{Pelaksanaan latihan}

Pelaksanaan latihan reactive agility sprint drill dengan bentuk pelaksanaan: pemanasan, latihan, dan pendinginan menurut Sinurat (2018) dapat dilihat pada tabel sebagai berikut :

Tabel 1. Pelaksanaan latihan reactive agility sprint drill

\begin{tabular}{cccc}
\hline .Waktu & Pemanasan & Latihan & Pendinginan \\
\hline Minggu 1 dan 2 & 10 menit & 30 menit & 5 menit \\
Minggu 3 dan 4 & 15 menit & 35 menit & 10 menit \\
Minggu 5 dan 6 & 20 menit & 40 menit & 15 menit \\
Minggu 7 dan 8 & 25 menit & 45 menit & 20 menit \\
\hline
\end{tabular}

\section{Teknik Analisis Data}

Analisis data yang digunakan yaitu harus dilakukan uji prasyarat sebelum dilakukan uji T-test. Uji prasyarat tersebut adalah uji normalitas dan uji homogenitas.

\section{HASIL DAN PEMBAHASAN}

Tabel 2. Data Perbandingan Hasil Pretest dan Postest

\begin{tabular}{cc}
\hline Hasil & Rata - rata \\
\hline Pretest & 4.57 \\
Posttest & 4.41 \\
\hline
\end{tabular}

Tabel 3. Uji normalitas dan uji homogenitas hasil pre dan post kecepatan

\begin{tabular}{cccc}
\hline Kelompok & $\boldsymbol{\Sigma}$ & Uji normalitas & Uji homogenitas \\
\hline Pre kecepatan & 12 & 0,723 & 0,131 \\
Post kecepatan & 12 & 0,166 & 0,146
\end{tabular}

Uji normalitas menggunakan One-Sample Kolmogorov-Smirnov Test.

Pada uji tersebut menunjukkan bahwa dari hasil pre dan post kecepatan adalah $\mathrm{p}=0,723(\mathrm{p}>0,05)$ dan $\mathrm{p}=0,166(\mathrm{p}>0,05)$, sehingga dapat disimpulkan jika data berdistribusi normal. Uji homogenitas menggunakan Lavene Test. Pada uji tersebut diperoleh hasil bahwa data homogen, dibuktikan dengan angka 
Ramadhany Hananto Puriana ${ }^{1)}$, Riga Mardhika ${ }^{2)}$. Jp.jok (Jurnal Pendidikan. Jasmani, Olahraga dan Kesehatan). 4(1)

signifikan pre $p=0,131(p>0,05)$ dan post $p=0.146(p>0,05)$. Yang berarti jika data tersebut memiliki varians yang sama atau homogen pada tiap tim.

Tabel 4. Hasil uji - T dari variabel dependent

\begin{tabular}{cc}
\hline Variabel & Nilai p \\
\hline Kelompok eksperimen & 0,003 \\
Kelompok kontrol & 0,000 \\
\hline$j \mathrm{j}$ - T dari variabel dependent & pada kelompok eksperimen
\end{tabular}

menunjukkan angka signifikansi $p=0,003(\mathrm{p}<0,05)$, artinya terdapat pengaruh signifikan. Hasil uji - $\mathrm{T}$ dari variabel dependent pada kelompok kontrol menunjukkan angka signifikansi $\mathrm{p}=0,000(\mathrm{p}<0,05)$, artinya terdapat pengaruh signifikan.

Membaca hasil uji - T diatas diketahui ada selisih hasil dari variabel terikat sebelum dan sesudah mendapatkan perlakuan yaitu kecepatan baik pada regu ekperimen maupun pada regu kontrol. Hasil tersebut membuktikan yakni masing- masing variabel meningkat secara signifikan, ditunjukkan dengan angka signifikansi $\mathrm{p}=0,000(\mathrm{p}<0,05)$. Dangan diberi Pelatihan sprint mirror drill bisa menambah tingkat kecepatan.

\section{Hasil Uji Hipotesis}

Dalam menguji hipotesis penelitian tentang pengaruh latihan reactive agility sprint mirror drill ini adalah menggunakan Uji-t atau paired t-tes melalui aplikasi SPSS versi 24. Hasil uji beda variabel Dependent Kelompok Eksperimen adalah $\mathrm{p}=0,003(\mathrm{p}<0,05)$, sehingga kesimpulannya terdapat pengaruh signifikan antar variabel Dependent di Kelompok Eksperimen, sedamgkan hasil uji beda variabel Dependent pada Kelompok kontrol diperoleh nilai $\mathrm{p}=0,000(\mathrm{p}<0,05)$, kesimpulanya juga terdapat pengaruh signifikan antar variabel Dependent di Kelompok kontrol.

Hasil uji hipotesis menyebutkan bahwa terdapat pengaruh signifikan sebelum dan sesudah diberi pelatihan pada tiap variabel terikat. Pelatihan reactive agility sprint mirror drill memberikan perbedaan hasil sesudah diberi pelatihan.

Pelatihan yang diterapkan secara terprogam selama 36 kali dengan menerapkan latihan reactive agility sprint mirror drill ternyata dapat membuktikan bahwa mahasiswa semester 6 di UNIPA Sby mengalami 
peningkatan kecepatan. Pengembangan kemampuan gerak cepat benar-benar didapatkan dari hasil pelatihan reactive agility sprint mirror drill. Terjadi peningkatan kelincahan yang lebih besar dari pada sebelumnya pada Mahasiswa yang mendapatkan latihan reactive agility sprint mirror drill sebanyak 36 kali latihan. Seorang atlet dikatakan terlatih jika sudah mengikuti beberapa rangkaian proses latihan selama kurang lebih $36 \mathrm{kali}$, hal ini didasarkan karena adanya perubahan pada atlet tersebut secara menetap (Hermassi et al., 2014)

Speed ialah keahlian seseorang dengan bergerak atau berpindah dari anggota badan dari satu tempat ke tempat yang lainnya atau untuk melakukan suatu kegiatan fisik yang diulang -ulang sama serta berkelanjutan dalam waktu yang sangat cepat (Ojakaa et al., 2014) . Kecepatan merupakan sebuah gerakan atau perjalanan yang dalam waktu singkat mampu mencapai jarak yang Panjang (Amar, Subarkah \& Wardoyo, 2017) .

Penambahan kecepatan dalam gerak bisa dilihat dari hasil membandingkan nilai mean pada pretest dan posttest. Data nilai mean pretest kecepatan adalah 4.75 detik, sedangkan hasil rata-rata posttest nya adalah 4.45 detik, selisih keduanya adalah 10.62 detik. Hal ini menunjukkan adanya perubahan lebih baik dari sebelum diberikan treatment sebesar 1.06\%, membuktikan bahwasanya pelatihan reactive agility sprint mirror drill pada kecepatan mendapatkan peningkatan yang signifikan.

Dari hasil-hasil riset tersebut menunjukan sangat jelas menyeluruh kalau pelatihan reactive agility sprint mirror drill sangat bisa memberikan dampak yang sangat positif dalam penambahan kecepatan. Dari sekian banyak metode Pelatihan untuk menambah kecepatan, reactive agility sprint mirror drill bisa dijadikan alternatif untuk diterapkan para pelatih yang ingin atletnya kecepatanya meningkatan apabila dilakukan secara teratur dan terprogram.

Titik fokus dalam gerakan dan reaksi yang cepat dimiliki oleh latihan reactive agility sprint mirror drill dalam sebuah cabang sepakbola. Peralatan cone digunakan peneliti dalam setiap kegiatan latihan atau treatment di setiap pertemuan sebagai perangkat utama, tujuannya agar fungsi-fungsi dari sistem organ tubuh manusia mengalami peningkatan kualitas, dan para olahragawan 
Ramadhany Hananto Puriana ${ }^{1)}$, Riga Mardhika ${ }^{2)}$. Jp.jok (Jurnal Pendidikan. Jasmani, Olahraga dan Kesehatan). 4(1)

dapat dengan mudah menyempurnakan gerakan - gerakan yang akan dilakukan. Hasil yang baik dan optimal akan didapatkan jika kegiatan latihan dapat dilaksanakan secara teratur dan disertai dengan prinsip latihan yang baik. Penggunaan metode latihan reactive agility sprint mirror drill dalam penelitian ini memiliki dampak yang signifikan pada penambahan kecepatan untuk cabang olahraga sepakbola.

\section{SIMPULAN}

Berdasarkan pembeberan dari hasil riset tersebut dan pengkajian yang sudah dijelaskan pada bab-bab sebelumnya, dari situ bisa disimpulkan, bahwa penelitian ini mempunyai hasil yang signifikan. Dapat dibuktikan dengan adanya hasil dari latihan reactive agility sprint mirror drill mempunyai kontribusi yang sangat signifikan terhadap kecepatan.

\section{DAFTAR RUJUKAN}

Ali Maksum. (2012). Metodologi Penelitian dalam Olahraga. Surabaya : UNESA University Press.

Amar, I. Y., Subarkah, A., Wardoyo, H. (2017). Pengaruh latihan SAQ (Speed, Agility, Quickness) terhadap peningkatan kelincahan atlet bulutangkis kelompok umur ganda remaja puteri PB.Djarum. Jurnal Ilmiah Sport Sport Coaching and Education, 1(1), 60-70. https://doi.org/10.21009/JSCE.01105

Bompa, Tudor O., \& Buzzichelli, C. (2018). Periodization-6th Edition: Theory and Methodology of Training. USA : Human Kinetics. https://doi.org/10.1207/S15327051HCI1523_6

Dr. Widiaastuti, M. P. (2015). Tes dan pengukuran olahraga. Jakarta : UNJ University Press. https://doi.org/10.1002/jmv.10345

Effendi, A. R., \& Rhamadhansyah, F. (2017). Peningkatan Pembelajaran Menggiring Bola dalam Permainan Sepakbola Menggunakan Modifikasi Bola Plastik. Jurnal Pendidikan Olahraga, 6(1), 54-64. http://dx.doi.org/10.31571/jpo.v6i1.574

Haugen, T. A., Tønnessen, E., Hisdal, J., \& Seiler, S. (2014). The role and development of sprinting speed in soccer. In International Journal of Sports Physiology and Performance, 9(3), 432-441. https://doi.org/10.1123/IJSPP.2013-0121

Henry, G., Dawson, B., Lay, B., \& Young, W. (2012). Effects of a feint on reactive agility performance. Journal of Sports Sciences, 30(8), 787-795. 
https://doi.org/10.1080/02640414.2012.671527

Hermassi, S., Gabbett, T., Spencer, M., Khalifa, R., Chelly, M., \& Chamari, K. (2014). Relationship between explosives performance measurements of the lower limb and repeated shuttle-sprint ability in elite adolescent handball players. International Journal of Sports Science and Coaching, 9(5), 11911204. https://doi.org/10.1260/1747-9541.9.5.1191

Ruslan. (2011). Meningkatkan Kondisi Fisik Atlet Pusat Pendidikan dan Latihan Olahraga Pelajar (PPLP) di Provinsi Kalimantan Timur. Jurnal Ilara, 2(2), 45-56. https://doi.org/10.1017/CBO9781107415324.004

Satriya. (2011). Pembinaan Kondisi Fisik. In Joint Conference UPI-UITM 2011 "Strengthening Research Collaboration on Education."

Sinurat, R. (2018). Pengaruh Metode Latihan S-Curve Runs Terhadap Peningkatan Kecepatan Lari 100 Meter Ditinjau Dari Rasio Panjang Telapak Kaki dan Tinggi Badan. Jurnal Ilmiah Edu Research, 7(1), 49 - 53. https://doi.org/12.1154/17843-8798.6.5.1194

Sporis, G., Milanovic, L., Jukic,I., Omrcen, D. \& Molinuevo, J.S. (2010). The effect of agility training of athletic power performance. Kinesiology, 42 (1), 65-72. https://doi.org/42.1123/78392-7382.6.4.6572

Sugiyono. (2013). Metode Penelitian Pendidikan Pendekatan Kuantitatif dan Kualitatif. Bandung : Alfabeta https://doi.org/10.1007/s13398-014-01737.2

Sukadiyanto, \& Muluk, D. (2011). Pengantar Teori dan Metodologi Melatih Fisik. Bandung : Lubuk Agung.

Turner, A. N., \& Stewart, P. F. (2014). Strength and conditioning for soccer players. Strength and Conditioning Journal, 36 (4), 1-13. https://doi.org/10.1519/SSC.0000000000000054

Kusnanik, N.W., Widiyanto, W. E., \& P. Bird, S.P. (2019). Effect of Reactive Agility Training Drills on Speed and Agility in Indonesian University Students. The Journal of Social Sciences Research, 5 (8), 1272-1275. https://doi.org/10.32861/jssr.58.1272.1275

Widiyanto. (2014). Respon Kardiovaskuler Akibat Latihan. Medikora, 4 (1), $24-$ 46. https://doi.org/10.21831/medikora.v0i1.4710

Young, W., \& Rogers, N. (2014). Effects of small-sided game and change-ofdirection training on reactive agility and change-of-direction speed. Journal of Sports $\quad$ Sciences, $32 \quad$ (4), 307-314. https://doi.org/10.1080/02640414.2013.823230 